\title{
Ion Beam Modification of Biodegradable Polymeric Biomaterials
}

\author{
Emel Sokullu* \\ Department of Engineering Sciences, İzmir KatipÇelebi University, Turkey
}

Submission: February 07, 2017; Published: February 13, 2017

*Corresponding author: EmelSokullu, Department of Engineering Sciences, İzmir KatipÇelebi University, Havaalanı Şosesi Cd. No:33 D:2, 35620 Çiğli/İzmir, Turkey, Email: emelsu@gmail.com

\section{Opinion}

In the last years biologically stable biomaterials gives their place to biodegradable biomaterials in packaging, agriculture, medicine, and other application areas. For applications in medicine this happens because of the some problems caused by the regeneration ability of the living tissues and toxic effect of stable polymers. By products of biodegradable polymers leaves no residual mass at the application site. This makes these polymers biocompatible which is very important for host response.

Biodegradable polymers can be classified mainly into two major groups: natural and synthetic biodegradable polymers. Both synthetic and natural polymers have been extensively investigated as biodegradable polymeric biomaterials. Biodegradation mechanism of polymeric biomaterials involves cleavage of hydrolytically or enzymatically sensitive bonds in the polymer leading to polymer erosion [1] . Depending on the mode of degradation, polymeric biomaterials can be further classified into hydrolytically degradable polymers and enzymatically degradable polymers. Most of the naturally occurring polymers undergo enzymatic degradation. There are several methods have been used to change of biodegradation period of this polymeric biomaterials. In recent years, ion beam modification technics are extensively used for this aim.

Ion implantation as an ion beam modification technic, is an effective surface modification method which uses energetic ions to alter the outermost surfaces of polymers without affecting their bulk properties [2]. Ion implantation consists of basically two steps:

A. Form plasma of the desired material, and either

B. Extract the positive ions from the plasma and accelerate them toward the target or find a means of making the surface to be implanted as the negative electrode of a high voltage system.
C. The system to form the plasma is called the ion source; the system to move the ions to the target is called the delivery system. The combination of the ion source and the delivery system is called the accelerator.

Nitrogen Ion Implantation for surface modification of metals was pioneered in the United Kingdom (UK) by Harwell Laboratory in the early 1970s. Nitrogen was chosen because the intense nitrogen beams are easily produced. In a typical direct nitrogen ion implanter nitrogen gas is fed into the ion source, where electrons emitted from a hot filament to ionize the nitrogen atoms and molecules, forming plasma. Nitrogen ions are then accelerated through a voltage drop, typically about $100 \mathrm{keV}$. The accelerated beam of nitrogen ions is directed at the surface of the part to be implanted in the vacuum chamber.

Metal Vapor ion implantation is a recent development among the ion implantation techniques. The technological development that led to the development of this process was the invention of the metal vapor vacuum arc (MEVVA) ion source at Lawrence Berkeley Laboratory ISM technologies in San Diego (BDM Federal Inc 1996) [2]. The plasma in a MEVVA ion source is generated by a cathodic arc or vacuum arc. The arc produces a very small ( 1 micron in diameter) cathode spot on the surface of an ion-forming metal that is colocated in the source and acts to create a broad beam of ionized metal vapor that is directed toward the target workpiece [2]. Ion beam methods preferentially used for creating biocompatible and bioactive surface coatings and interfaces which can promote and stabilize cell attachment for medical instruments and biomaterials.

As an example in literature to ion beam modification of biodegradable polymers, Yotoriyama, T. and coworkers have worked on the analysis of cell-adhesion surface induced by ion-beam irradiation into biodegradable polymers $[3,4]$. They mediate the cell adhesion by the formation of an adsorbed interfacial protein layer coming from the complex serum medium. 
They performed Ar+ ion-beam irradiation into PLLA at energy of $50 \mathrm{keV}$ with fluencies of $1 \mathrm{x} 1014$ and $1 \mathrm{x} 1015 \mathrm{ions} / \mathrm{cm} 2$ at room temperature using a RIKEN $200 \mathrm{kV}$ low current implanter [3]. Non-irradiated PLLA sheets were used as controls in all investigations. Protein adsorption on an ion-irradiated surface was investigated using a fluorescence antibody technique. As a result, adsorption on the irradiated surface increased relative to the non irradiated surface.

Takano, I., were also modifying the biodegradable polymers surfaces by using ion beam modification. For the experiment, polylactic acid (PLA) was selected as the biodegradable plastic with high transparency [5]. The biodegradable plastic was bombarded by $\mathrm{Ar}+$ or $\mathrm{He}+$ ions with ion energy of $2 \mathrm{keV}$ and ion current density of $20 \mathrm{~mA} / \mathrm{cm} 2$. At the end of the study they found the hardness of the biodegradable plastic increased by $\mathrm{He}+$ ion bombardment, which modified a thicker layer comprising of the $\mathrm{C}-\mathrm{C}$ structure than $\mathrm{Ar}+$ ion bombardment. The biodegradable plastic bombarded at ion energy of $10 \mathrm{keV}$ performed high transmittance of a visible ray and interception of an ultraviolet ray by a modified layer.The deterioration of hardness by an ultraviolet ray was effectively protected by using $\mathrm{He}+$ ion bombardment [5].

In another study, ion beams were irradiated into biodegradable polymer sheets to develop thin film, selfassembled cellular sheets by T Yotoriyama, et al. [4]. He+ ion implanted at an energy of $150 \mathrm{keV}$ with a fluence of $1 \mathrm{x} 1015$ ions/ $\mathrm{cm} 2$ at room temperature using $200 \mathrm{kV}$ Low-Current Implanter. At the end of the their study they found out that the structural change occurred near the maximum of energy deposition estimated by TRIM code and ion-irradiated region had gradient properties depending on localized energy deposition [4].

To evaluate whether or not the corneal micropocket implantation is effective for determining the toxicity of polymeric materials, Kobayashi et. al used biodegradable polymers such as poly(lactic acid) (PLA), poly (glycolic acid) (PGA), LAGA copolymers, and three kinds of poly (2-cyano-acrylate)s (PCA) [6] . These biodegradable polymers were implanted in a rabbit corneal pouch and the tissue responses were observed macroscopically and microscopically. In this study, it was found that PLA induced no vascularization, whereas a residual solvent and ethylene oxide gas remaining in the PLA matrix invoked vascularization. Vascularization clearly took place when PGA was implanted in the cornea, which became opaque, probably because of cellular infiltration. In the case of PCA implantation, severe inflammation as well as vascular invasion occurred in the initial stage. It is likely that these tissue reactions were caused by the leachables from the implanted materials, the extent being dependent on the leaching rate and the toxicity. It was concluded that the corneal micropocket assay is a good means to detect trace amounts of leachables from implanted materials without sacrificing the animals with the implanted materials [6].
The results of Kondyurin et. al. studies of ion implantation of PLGA show that the PLGA films undergo crosslinking, carbonization and etching [7]. The PLGA coating degrades in water by a hydrolysis reaction. The dewetting of PLGA coating under water is observed on silicon wafer, metal and carbon surfaces. As the result, the coating is ruptured up to separate drops of PLGA on the surface. The dewetting process can be eliminated by an ion beam implantation treatment, when the ions penetrate through the whole PLGA coating. The dewetting process in the modified layer can be eliminated even with low fluence 1014 ions / cm2modification. The amount of degradable PLGA in the modified layer depends on the fluence of ion implantation and can equal up to $80 \%$ of the film at low fluence of 1014 ions / cm2 [7].

In one of our study, we have shown that ion implantation of $\mathrm{C}$ and $\mathrm{Au}$ into biodegradable polymers, over a range of implantation fluences, modifies the polymer surface to produce oxygen-containing more hydrophilic surfaces [8]. Surfaces implanted at low and high fluences show the formation of less oxygen groups, while at intermediate implantation fluence, enhanced oxygenation is observed, possibly due to migration of species along chains and atmospheric effects. These results suggest that ion implantation at optimum fluence affects the behavior of biodegradable polymeric materials in highly oxidative environments [8].

Our results strongly indicate the influence of surface modification by ion treatment on cell attachment growth, cell proliferation and cellular morphology compared to unimplanted samples $[8,9]$. These results are important to show that we can create a viable environment for cells where they secrete their own extracellular matrix and show their own phenotype and morphology without getting stressed. We have a great control over the surface topology just by changing the ion dose value and energy which makes it possible to create desired surface structures for different applications [9].

In summary,several types of ion beam technics can be used for modification of biodegradable polymers. These ion beam modification tools may have been used for a large domain of applications especially in biomaterials field in order to controlling ability of biodegradation time and cell adhesion properties of the degradable polymers.

\section{References}

1. Autissier A, Le Visage C, Pouzet C, Chaubet F, Letourneur D (2010) Fabrication of porous polysaccharide-based scaffolds using a combined freeze-drying/cross-linking process. Acta Biomaterialia 6(9): 3640-3648.

2. Brown IG, Anders A, Dickinson MR, MacGill RA, Monteiro OR (1999) Recent advances in surface processing with metal plasma and ion beams. Surface and Coatings Technology 112(1-3): 271-277.

3. Yotoriyama T, Yoshiaki Suzuki, Takaya Mise, Takeyo Tsukamoto, Masaya Iwaki (2004) Surface characterization of thin film induced by $\mathrm{He}^{+}$ion- 
beam irradiation into PLLA. Surface \& Coatings Technology 196 (2005) 383-388.

4. Yotoriyama, T. et al. (2006) Nucl Instr and Meth in Phys. Res B 242 51-54.

5. Ichiro Takano, Yoshiharu Arai, Michiko Sasaki, Yoshio Sawada, Kaori Yamada, et al. (2006)Surface modification of biodegradable plastics by ion beams. 80(2006): 788-792.

6. Kobayashi H, Shiraki K, Ikada Y (1992) Toxicity test of biodegradable polymers by implantation in rabbit cornea. J Biomed Mater Res 26(11): 1463-1476
7. Kondyurin A, Kondyurina I, Bilek M (2011) Biodegradable drug eluting coating of cardiovascular stents dewets and can cause thrombosis. arXiv.org > physics > arXiv:1101.0659.

8. Sokullu-Urkac E, Oztarhan A, Tihminlioglu F, Nikolaev A, Brown IG (2012) Oxidation Behavior of C-and Au-Ion-Implanted Biodegradable Polymers. IEEE Transactions on Plasma Science 40(3): 863-869.

9. Emel Sokullu, Fulya Ersoy, Ahmet Öztarhan, Ian G Brown (2015) Controlling cell morphology on ion beam textured polymeric surfaces. Anatomy: International Journal of Experimental \& Clinical Anatomy $9(3)$.

\section{Your next submission with Juniper Publishers will reach you the below assets}

- Quality Editorial service

- Swift Peer Review

- Reprints availability

- E-prints Service

- Manuscript Podcast for convenient understanding

- Global attainment for your research

- Manuscript accessibility in different formats

( Pdf, E-pub, Full Text, Audio)

- Unceasing customer service

Track the below URL for one-step submission https://juniperpublishers.com/online-submission.php 